\title{
Migrações venezuelanas, crise da reprodução social capitalista e necropolíticas de fronteira
}

\section{Venezuelan migration, crisis of capitalist social reproduction and border necropolitics}

Ana Carolina G. Leite* Mariana de Araújo Castro**

Resumo: Nesse artigo, discutimos alguns aspectos das atuais migrações venezuelanas, chamadas também de diáspora venezuelana, relacionando-as à crise da reprodução social capitalistas e às necropolíticas engendradas por essa última. Para tanto, relacionamos tais migrações com o estouro da bolha que caracterizou o fim do boom das commodities e a crise mundial de 2008, que resultaram em uma brutal deterioração das condições de vida da população e ampliação da gestão armada da vida social na Venezuela; avançamos uma discussão crítica sobre os limites da distinção entre migrações forçadas e voluntárias; e observamos dimensões conflituosas do acolhimento recebido pelos venezuelanos no Brasil, levando em conta a gestão de populações e as políticas de fronteira. Para além do debate bibliográfico, da análise de documentos e matérias jornalísticas, sustentam ainda nossas reflexões, trabalhos de campo realizados pelas autoras a Roraima em 2019 e em 2020.

Palavras-chave: migrações venezuelanas; crise da reprodução social capitalista; gestão de populações.

Abstract: In this article, we discuss some aspects of the current Venezuelan migrations, also called Venezuelan diaspora, relating them to the crisis of capitalist social reproduction and the necropolitics engendered by it. To do so, we relate such migrations to the bursting of the bubble that characterized the end of the commodities boom and the 2008 global crisis, which resulted in a brutal deterioration of the living conditions of the population and the expansion of the armed management of social life in Venezuela; we advance a critical discussion on the limits of the distinction between forced and voluntary

\footnotetext{
* Doutora, Professora Adjunta do Departamento de Ciências Geográficas da UFPE.

** Mestra pelo programa de pós-graduação em Políticas Públicas em Direitos Humanos - NEPP DH UFRJ. Possui graduação em Defesa e Gestão Estratégica Internacional pela Universidade Federal do Rio de Janeiro.
} 
Revista Brasileira de História \& Ciências Sociais - RBHCS

Vol. 13 No 26, Janeiro - Junho de 2021

migrations; and we observe conflicting dimensions of the reception received by Venezuelans in Brazil, taking into account the management of populations and border policies. In addition to the bibliographical debate, the analysis of documents and journalistic reports, fieldwork conducted by the authors to Roraima in 2019 and 2020 also sustain our reflections.

Keywords: Venezuelan migrations; crisis of capitalist social reproduction; population management.

\section{Introdução}

Discutimos, nesse artigo, alguns aspectos das atuais migrações venezuelanas, relacionando-as à crise da reprodução social capitalista e às necropolíticas por ela engendradas. Para tanto, dividimos o texto em quatro partes principais, além de uma introdução e uma conclusão. Na primeira parte, partimos da polêmica sobre a relação entre as migrações venezuelanas, a crise e as sanções econômicas sofridas pelo país para começar a tatear explicações sobre generalizada deterioração das condições de vida sofridas por aquela população, que passou a se deslocar intensamente, sobretudo a partir de 2014. Fazemos um recuo histórico para abordar brevemente mudanças ocorridas durante o século XX na Venezuela, de maneira a discutir o contexto em que se deu a eleição de Hugo Chávez. Em seguida, passamos para uma discussão da forma de reprodução política e econômica do bolivarianismo, buscando investigar o processo de gestação da crise no país. Concluímos, então, com um debate crítico das interpretações que acusam rentismo e financeirização, tomando em conta o processo contemporâneo de crise da reprodução social capitalista.

Na segunda parte, caracterizamos as migrações venezuelanas em suas várias etapas e também as interpretações mais comuns do processo. Desse compilado, refletimos sobre a caracterização dos migrantes venezuelanos a partir da tradicional divisão entre migrações voluntárias e migrações forçadas, incluindo também a categoria do refugiado. Interpretando as migrações venezuelanas no bojo da crise da reprodução social capitalista, problematizamos a validade hodierna dos limites entre essas duas formas de pensar as migrações, considerando o processo generalizado de expulsões que se origina com aquela crise. 
Na terceira parte, por sua vez, analisamos a militarização que se intensifica como forma de gestão contemporânea de populações afetadas pela deterioração total de condições de sobrevivência ou deslocadas, sobretudo com foco na manutenção de uma estabilidade fronteiriça e regional. Assim, observamos pari passu o avanço do processo na Venezuelana e no Brasil, chegando à Operação Acolhida como síntese da militarização e da emergência do confinamento como padrão territorial de gestão de populações de crise.

Finalmente, na quarta parte, discutimos experiências de socialização de migrantes venezuelanos em suas jornadas, abordando as relações mediante as quais eles se reproduzem precariamente como uma necropolítica de fronteira. Além de debate bibliográfico sobre os temas, discussão e elaboração teórica e consultas a documentos e matérias jornalísticas, a argumentação contou ainda com os trabalhos de campo realizados em Roraima (Boa Vista e Pacaraima) em 2019 e 2020, quando foram realizadas visitas a abrigos, ocupações, instituições de acolhimento de migrantes, a observação participante e entrevistas em profundidade.

\section{Migrações venezuelanas: crise da Venezuela ou crise da reprodução social capitalista?}

Compreender as atuais migrações venezuelanas ou a diáspora venezuelana, como passaram a ser chamadas sobretudo a partir da intensificação ocorrida em 2015, exige retomar o processo que conduziu a uma pronunciada deterioração das condições de reprodução da população daquele país, ou seja, a crise da Venezuela. Hoje existe um largo campo de discussões sobre o assunto, com pesquisas que relacionam crise e migrações. Com respeito a esse tópico, destacam-se duas perspectivas principais, a saber, aquela que estabelece uma relação de causalidade entre as migrações e as sanções impostas ao país pelos EUA especialmente a partir de $2017^{1}$, e outra que a contrapõe,

\footnotetext{
${ }^{1}$ A Venezuela vinha sofrendo sanções dos EUA desde 2014 e em 2017 o quadro se aprofunda. Instituições financeiras e bancos americanos deixam de receber pagamentos em dólares e fecham contas de bancos venezuelanos, entre eles do Banco Central da Venezuela (BCV) e da estatal Petróleos de Venezuela (PDVSA), impedindo também transações para a compra de recursos de primeira necessidade, como alimentos e medicamentos. Com a Ordem Executiva 13808, promulgada pelos EUA em agosto de 2017, o governo venezuelano fica proibido de fazer novas dívidas com vencimento superior a 30 dias e a PDVSA, com vencimento superior a 90 dias. Este fica proibido também de receber lucros e dividendos por parte de empresas que operam em território americano, como a refinaria CITGO. Em fevereiro de 2018, os EUA proíbem credores internacionais de renegociar dívidas emitidas antes de agosto de 2017. Todos
} 
recusando que as sanções tenham levado à crise e ao deslocamento populacional em curso, que teriam resultado, antes, de equívocos e deficiências de gestão até o limite da total deterioração da reprodução no país.

A perspectiva que sustenta uma relação de causalidade entre sanções e migrações conclui, de maneira geral, que "el bloqueo explica la mayor parte de la crisis económica que afecta al país, que ha sido el principal causante de las migraciones" (CELAG, 2019, p. 1). Argumenta que a perda de receitas e divisas teria sido a maior responsável por empurrar a inflação alta para o quadro hiperinflacionário que se seguiu às sanções e que a privação da Venezuela do acesso necessário ao dólar para viabilizar as importações essenciais, ameaça vidas e impõe a fuga do território nacional como única opção de sobrevivência para parte significativa da população. Destaca, além disso, que o impacto mais significativo de tais sanções não recaiu sobre o governo, mas, sim, sobre a população civil, reduzindo ingestão calórica das pessoas e aumentando doenças e mortalidade, cuja subida entre 2017 e 2018 alcançou a assombrosa cifra de 31\% (WEISBROT; SACHS, 2019).

Já a contraposição a essa perspectiva, defende que a economia da Venezuela está declinando há anos e que o país, por encargo dos governos bolivarianos, já se encontrava quebrado e insolvente, o que veio provocando sistemáticas migrações cujo quadro não fora alterado pelas sanções. Relaciona crise e endividamento nacional durante a prosperidade petroleira e argumenta, inclusive, que as últimas emissões de bônus da dívida venezuelana, anteriores às sanções de 2017, com taxa de juros de $47 \%$ só poderiam ser pagas levando a população à fome (D" ERIZANS, 2019). Justifica, assim, as sanções, apesar de todas as gravíssimas implicações das mesmas, algumas delas reconhecidas, simplesmente por bloquearem o acesso ao mercado de capitais internacional para cessar o endividamento tido como irresponsável e lesarem governantes tidos como mafiosos (HAUSMANN, 2018).

Voltemos um pouco na história. Em 1998, Hugo Chávez vence o pleito máximo da Venezuela. Sua eleição representa a ruptura definitiva do acordo firmado 40 anos antes, conhecido como Punto Fijo, em substituição à sequência

os cidadãos ou instituições financeiras americanas ficam proibidas de fazer transações na criptomoeda Petro e investir em ativos venezuelanos. Em 2019, as importações americanas de petróleo venezuelano vão a zero, depois do país ter importado $35,6 \%$ da produção nacional no ano anterior e, além disso, os EUA pressionam outros países para que também deixem de importar, como a Índia (CELAG, 2019; WEISBROT; SACHS, 2019). 
ditatorial que marcara a primeira metade do século XX no país e para garantir estabilidade constitucional mediante pacto populista de conciliação com alternância entre os partidos Comité de Organización Política Electoral Independiente (COPEI) e Acción Democrática (AD) e distribuição clientelista da renda petrolífera que financiava o país pelo menos desde 1920 (VILLA, 2005).

A institucionalização dos interesses diversos de empresários, da igreja, das forças armadas e até de sindicatos ou pela incorporação de representantes de pequenos partidos excluídos do acordo no exercício de cargos de segundo escalão conferia-lhe estabilidade, embora a desigualdade social no país fosse gritante, com índices baixíssimo de acesso a educação, pensões e aposentadorias e bastante elevados de pobreza, pobreza extrema, subnutrição e mortalidade infantil (PAIVA, 2017; ZERO, 2017).

O sistema seria, contudo, bastante abalado em 1989, quando a população sai às ruas massivamente para repudiar o pacote econômico exigido pelo FMI, bem aos moldes do Consenso de Washington, no então denominado Caracazo. Meses antes, em fins de 1988, Carlos Andrés Pérez, socialdemocrata da AD, fora eleito com a memória de seu governo anterior, entre 1973 e 1978, cuja bonança derivou da primeira grande escalada nos preços internacionais do petróleo, o que o permitiu nacionalizar aquela indústria, em 1976. Sem embargo, com a crise que se pronuncia por toda a América Latina a partir da década de 1980, ele assume as reformas neoliberais, incluindo ajustes fiscais, privatização de empresas estatais e enxugamento da máquina administrativa. E oferece repressão militar intensa frente as manifestações de insatisfação popular, provocando grande número de mortes (VILLA, 2005).

$\mathrm{Na}$ esteira dos conflitos, em 1992, um grupo de oficiais liderados por Hugo Chávez protagoniza uma tentativa de golpe e, em 1993, Pérez é afastado do governo acusado de corrupção. Ante o vazio político advindo com o enterro do puntofijismo, grande parte da população recebe bem as iniciativas chavistas o que vai fazendo com que ele recuse a perspectiva inicial do golpe ou conclame da abstenção eleitoral em direção à proposta de modificação das instituições de dentro para fora e de uma constituinte. Surge o Movimento Quinta República (MRV) e a eleição de Chávez em 1998 é síntese da rejeição aos partidos 
tradicionais (VILLA, 2005) e da proposição de uma espécie de terceira via²

Chávez torna-se presidente em 1999 e no mesmo ano promove eleições para uma Assembleia Nacional Constituinte, as quais vence da oposição por esmagadora maioria. Há inúmeras reformas político-institucionais, dentre elas a instauração da possibilidade de o executivo legislar por decreto em temas e pelo tempo definido por parlamentares. Eram as chamadas leis habilitantes. Dentre as 49 aprovadas em 2000, as leis da Pesca, de Terras e Desenvolvimento Agrário e dos Hidrocarbonetos, fazem eclodir um movimento acirrado de oposição ao chavismo, porque limitam a apropriação privada e incitam a reapropriação pelo Estado da renda petrolífera em um país em que parte substancial das divisas advinham do petróleo (SCHURSTER; ARAUJO, 2015).

Ante grande pressão golpista, Chávez se entrega, vai preso, mas um movimento em defesa da legitimidade do seu governo e das reformas se massifica e reverte a situação. Acontecem greves patronais no setor petroleiro que derrubam o PIB do país em 17\%, produzindo um considerável déficit no caixa público e altos índices de desemprego. Não obstante, o presidente sai daquela crise fortalecido, com apoio popular e militar para nacionalizar o petróleo e demitir/substituir $17 \mathrm{mil}$ dos 42 mil funcionários dessa indústria, enquanto a oposição termina fragmentada. Ele retoma governabilidade com a criação das chamadas Misiones, programas sociais abrangentes 3 , com grande participação popular e presença militar, financiados com recursos do petróleo (SANTOS, 2019).

A primeira derrota eleitoral do chavismo ocorrerá só em 2007, quando tenta aprovar sem sucesso reformas constitucionais que ampliariam o poder do executivo. A oposição aproveita o momento e se organiza na Mesa de Unidade Democrática (MUD), a partir da qual reinsere-se nos pleitos. As eleições parlamentares de 2011 evidenciam menor adesão da população ao governo, embora em 2012 Chávez se eleja pela terceira vez consecutiva, vencendo o

\footnotetext{
${ }^{2}$ Embora se associe frequentemente a base da campanha eleitoral chavista à refundação da Venezuela, ao antineoliberalismo e ao combate à pobreza (SCHURSTER; ARAUJO, 2015), alguns autores destacam a necessidade de relacionar isso à reivindicação do "Estado quanto seja necessário e mercado quanto seja possível" durante e após as eleições, por exemplo, no Programa Econômico de Transição 1999-2000, de autonomia para o BCV e de Tony Blair e Bill Clinton como referências (BARROS, 2007).

3 As Misiones Bolivarianas compreenderam programas de acesso a alimentação, renda, educação, alfabetização, consultas médicas gratuitas, subvenção de créditos para aquisição de habitação, etc.
} 
empresário Henrique Capriles por 55,8\% dos votos, mas não chega a assumir o cargo em função de tratamento médico do câncer que o leva a morte em 2013. A sucessão governamental ocorre de forma conturbada, sob acusações de inconstitucionalidade, e, após novas eleições, Nicolás Maduro, herdeiro do legado de Chávez, se elege, outra vez sobre o oposicionista Capriles, porém com a estreita margem de 50,75 a 48,97\% (SANTOS, 2019).

Nesse período, o chavismo modificou o quadro de desigualdade social venezuelano. Entre 1998 e 2012, a pobreza diminuiu de 43,9 para 21,1\% e, a pobreza extrema, de 17,1 para 6\% dos domicílios. Diminuiu também a concentração de renda, como mostra a queda no índice de Gini de o, 489 para 0,404, nível de países como os EUA (PAIVA, 2017). Na base de tais mudanças e do impulsionamento vivido pelo país como um todo esteve não apenas o citado financiamento petrolífero que sempre caracterizou a Venezuela, mas sobretudo o aumento substantivo dos preços do petróleo, no contexto conhecido como boom das commodities.

Entretanto, com o estímulo do boom e da grande disposição do mercado de capitais globalizado em disponibilizar recursos, entre 2006 e 2012, em apenas seis anos, o país quadruplicou sua dívida pública externa. Uma fonte relevante de tais empréstimos foram os bancos de desenvolvimento chineses, no qual metade das dívidas foi tomada com prazos curtíssimos de três anos e os pagamentos acordados em remessas de petróleo. Também em 2012, antes que o preço do petróleo despencasse, a Venezuelana já havia esgotado quase totalmente seu montante de reservas internacionais líquidas, com limitações para o fluxo de entrada maiores que para o de saída ${ }^{4} \mathrm{e}$ elevados gastos com $o$ serviço da dívida5 (VERA, 2018).

Diante da considerável restrição de divisas, recorrer-se-ia, já no governo Maduro, ao corte de importações, saída bastante custosa para economia e sociedade, uma vez que elas haviam triplicado entre 2004 e 20086. Esse

\footnotetext{
4 Esse esgotamento vinculou-se a uma reforma ocorrida em 2005 no BCV. Ela permitiu, por um lado, que o governo se apropriasse de quantias importantes de reservas internacionais e repassá-las para o Fundo de Investimentos do Setor Público (FONDEN). E, por outro, anulou a cláusula segundo a qual a PDVSA tinha obrigação de vender as divisas de origem petrolífera ao BCV pela taxa de câmbio oficial, permitindo que a empresa concentrasse poder sobre aqueles recursos (VERA, 2018).

5 Em 2011, esses gastos corresponderam a quase 20\% dos recursos totais obtidos com as exportações. Em 2015, chegaram a 55\% (VERA, 2018).

${ }^{6}$ Sem dúvida, 2014 comporta uma piora grave do quadro, com a queda do preço do barril de
} 
aumento teve relação direta com a perda da competitividade da produção nacional devido à sobrevalorização do bolívar que a política cambial de controle da inflação causou. Historicamente, para remediar as pressões inflacionárias e para limitar a fuga de capitais, congelava-se artificialmente o dólar7. Essa dinâmica seria confrontada depois, com ações de desvalorização do bolívar, mas sempre em grau insuficiente para compensar a sobrevalorização real da taxa de câmbio (PAIVA, 2017).

O corte de importações que vai abalar profundamente consumo direto e indireto alcançaria a proporção de quase $76 \%$ em 2017. Generaliza-se, assim, a falta de alimentos, remédios e insumos médicos. Passam a faltar também insumos para a produção de bens nacional, afetada ainda pela queda nos salários reais que inibe qualquer retroalimentação e ocorre acompanhando alta inflacionária e derrocada de 39,5\% no PIB, também em 2017. Finalmente, nesse ano o câmbio real descola-se do nominal, sobe em 1.825\% no mercado paralelo ilegal e se torna o principal indexador dos preços de importação (VERA, 2018).

Quando o ano chega ao fim, não há mais reservas líquidas, os reduzidos ingressos petrolíferos não são suficientes nem para fazer importações nem para saldar dívidas e seus serviços, as sanções não permitem nenhuma renegociação e o país chega à hiperinflação de média mensal $62 \%$. Agravam-se condições de reprodução já absolutamente deterioradas. Segundo a Encuesta Nacional de Condiciones de Vida (ENCOVI), ainda em 2016, 80\% dos domicílios tornam-se pobres e 10 milhões de pessoas vão à pobreza extrema (VERA, 2018).

Essa síntese bastante abreviada contribui para evidenciar alguns dos fenômenos que culminaram na generalização das migrações ou, como dissemos, da fuga como opção de sobrevivência única. A parte toda realidade dos dados, eles também revelam, todavia, uma perspectiva que busca explicar a crise colocando em questão a extrema dependência da economia do recurso natural exportável, o dinamismo quase nulo do setor privado não petrolífero, a alta dependência de importações, o caráter deficitário da gestão fiscal e os elevados

petróleo de US\$ 114,92, em junho, para US\$ 46,59 em janeiro do ano seguinte. G1. Entenda a queda do petróleo e seus efeitos, Economia, 2015. Disponível em: https://glo.bo/3tLWTOy, acesso em: 18/03/2021.

$7 \mathrm{O}$ aumento dos preços do petróleo foi, em geral, responsabilizado pelas pressões inflacionárias estruturais do período bem como o progressivo predomínio do petróleo na pauta de exportações. Paiva (2017) aponta um aumento de 72\%, em 1998, para 99\%, em 2012. Lander (2017), de 68,7\%, em 1998, para 96\%, em 2013. Esse último menciona ainda a redução na participação do setor industrial no PIB de 17\% em 2000 para 13\% em 2013. 
gastos com a administração pública, para além da queda dos preços da commodity ${ }^{8}$.

Nada disso é falso, como mostram os dados. Trata-se, ainda assim, de discutir os pressupostos desenvolvimentistas e industrialistas que estão na base dessa perspectiva. Parece haver um problema de ordem estritamente política. Para sustentar os programas sociais e preservar o apoio eleitoral, mantendo pela via mais fácil o projeto de poder chavista, consolida-se o caráter rentista na economia, herdado de períodos anteriores (LANDER, 2017). Opção distinta seria fortalecer o desenvolvimento interno autossustentado, investindo em indústria nacional para tornar o país menos dependente da importação e criar um ciclo virtuoso em que os investimentos da renda petroleira retornam e induzem à produção de riqueza, de preferência sem limitação aos ganhos privados, dado que só desestimularia as inversões (VERA, 2018).

$\mathrm{Na}$ maior parte das vezes, os argumentos em questão nem chegam a revelar como o rentismo não foi simplesmente dos governos bolivarianos, mas, sim, do capital financeiro, que intermediava a indústria de petróleo por meio do endividamento, mesmo tendo sido nacionalizada a produção, conforme análises consagradas por certa tradição crítica brasileira (BELLUZZO, 2012; PAULANI, 2017). Para esta, o declínio da produção industrial que também foi verificado no Brasil durante o período, diferente de ser atravessado por mero proveito político, relaciona-se com o processo contemporâneo de mundialização e financeirização da economia, que atualiza uma histórica dependência, sendo de fato o responsável pela regressão produtiva e reprimarização. Essa leitura, ainda que avance com relação aos limites primeiro identificados, tem ainda o problema considerar que o capital financeiro ou mina o desenvolvimento do capital produtivo ou o "explora", impondo uma dinâmica de apropriação pelas finanças do centro da produção de riqueza das periferias.

Assim, desconsidera, como toda leitura desenvolvimentista e industrialista, que a dificuldade em recriar ciclos virtuosos de modernização nacional passa hoje sobretudo pela crise fundamental que abrange a produção capitalista em seu conjunto. Níveis cada vez mais elevados de produtividade

${ }^{8}$ Essa perspectiva é evidente em Paiva (2017) e Vera (2018), nos quais recolhemos boa parte dos dados. Mesmo em Lander (2017), cuja argumentação busca se diferenciar dos primeiros, fazendo um balanço de esquerda dos avanços e retrocessos do bolivarianismo, contudo, o mesmo é caracterizado por menções sistemáticas à doença holandesa, ao aprofundamento do modelo petroleiro-exportador rentista e à corrupção e à inépcia. 
promoveram expulsão relativa e absoluta do trabalho vivo do processo produtivo tornando a reprodução do capital dependente de forma estrutural de montantes cada vez maiores crédito cuja promessa de realização futura se cumpre apenas mediante novas rodadas de crédito, em um processo de autonomização entre o dinheiro e a riqueza socialmente produzida, que ficcionaliza a reprodução do capital9 (KURZ, 2014).

Contudo, ocorre justamente que essas novas rodadas de crédito são dificultadas pela deflação geral de ativos financeiros e preços das commodities que tem início em 2008 e se aprofunda em 2014, quando colapsam os circuitos globais de déficit sustentados no endividamento dos $\mathrm{EUA}^{10}$. O que o processo revela, ao invés de um suposto boom das commodities, é a inflação desmedida de títulos de propriedade (e como resultado, dos preços das commodities) em bolhas cujo estouro levaria ao limite as vias de sentido único de exportação dependentes de crédito americano e a dependência estrutural venezuelana da rolagem de suas dívidas, trazendo à tona o processo mundial de ficcionalização do capital, acima mencionado (KURZ, 2014).

\section{Migrações venezuelanas e crise do limite entre migrações}

\section{voluntárias e forçadas}

Grande parte da produção acadêmica e de documentos e normativas dos organismos internacionais ou Estados nacionais dividem as migrações em voluntárias ou forçadas, considerando as motivações que levam as pessoas a migrar. De acordo com a Organização Internacional para Migrações (OIM), não existe nenhuma definição legal para a categoria "migrante" e o ato de migrar é interpretado como um processo voluntário, relacionado basicamente a questões econômicas e laborais ${ }^{11}$. As migrações voluntárias seriam, assim, caracterizadas

\footnotetext{
9 Esse processo pode ter sido ocultado na Venezuela circunstancialmente pelo declínio da produção e da produtividade petroleira para favorecer o aumento dos preços do petróleo no contexto do boom das commodities (BARROS; PINTO, 2012), mas levaria à ruína também o Brasil, apesar do incremento em ambas nos principais setores exportadores, como o agronegócio (PITTA et al. 2020). Além disso, é notável que a crise de 2008 tenha se iniciado justamente nas economias centrais, onde concentram-se os maiores diferenciais de produtividade.

1o Por isso, não para justificar em nenhuma medida às sanções impostas à Venezuela, problematizamos a ideia de que a reestruturação do endividamento daquele país se deva exclusivamente a elas.

${ }^{11}$ Ver verbete migrant no Glossário da OIM. Disponível em: https://bit.ly/3cyOcBy, acesso em: 18/03/2021.
} 
pelo caráter espontâneo da decisão daqueles migram ${ }^{12}$. Em contraposição a elas haveria ainda, segundo a Organização das Nações Unidas (ONU), migrações involuntárias realizadas por refugiados e solicitantes de refúgio, deslocados internos, apátridas e asilados ${ }^{13}$.

Por esse prisma, a visão dominate na sociedade e, não raro, entre os próprios migrantes sobre o ato de migrar considera-o positivo e uma promessa de progresso pessoal. Já que a escolha partiria de um balanço entre os prós e contras do deslocamento em busca das melhores condições de trabalho, de renda ou de vida, a migração daria ao indivíduo chance de exercer sua liberdade em busca de benefícios. Migrar aparece, assim, como uma espécie de investimento para atingir bons resultados. Para o raciocínio liberal e sua suposta defesa da circulação livre, o espaço abstrato e isonômico, por um lado, e indivíduos e/ou famílias, por outro, seriam as bases de uma decisão de caráter racional (LEITE et al. 2017).

Face a essa imagem id ilica contrapõe-se, contudo, a coação como base central da mobilidade, numa forma social em que pessoas desenraizadas são, em grande medida, submetidas a arranjos de exploração e exclusão ou culpabilizadas se não alcançarem seus objetivos. Expropriadas dos meios de produção ou de sobrevivência, a reprodução desses despossuídos passa a depender essencialmente da venda de suas forças de trabalho ${ }^{14}$. Produz-se, assim, a mobilidade do trabalho (GAUDEMAR, 1977) como premissa simultânea da reprodução dos trabalhadores, da reprodução do capital, das migrações e de quaiquer outras formas de deslocamento. A suposta liberdade

\footnotetext{
${ }^{12}$ A legislação brasileira vigente, Lei no ${ }^{0} 13.445 / 2017$, define imigrante como "pessoa nacional de outro país ou apátrida que trabalha ou reside e se estabelece temporária ou definitivamente no Brasil. Disponivel em: https://bit.ly/3ddDkIo, acesso em: 18/03/2021.

${ }_{13}$ De acordo com a Convenção das Naçooes Unidas sobre o Estatuto dos Refugiados (1951), define-se refugiado qualquer pessoa que por razão de perseguições políticas, raciais, religiosas, de nacionalidade ou grupo social necessita sair de seu páis de origem e, por isso, não pode ounão quer recorrer a proteção do mesmo. Há também o Protocolo de 1967 relativo ao Estatuto do Refugiado que surgiu posteriormente com o objetivo de suprimir a cláusula temporal presente na Convenção de 1951, abarcando novos contextos que produzem solicitações de refúgio. No cenário latino-americano destaca-se a Declaracão de Cartagena (1984) que ampliou esta categoria a pessoas submetidas a violência generalizada, agressão estrangeira, conflitos internos, violação sistemática dos direitos humanos ou outras circunstâncias que tenham perturbado gravemente a ordem pública . No Brasil, o marco de proteção aos refugiados é a Lei no 9.474/97 e segue as orientações das declarações citadas.

14 Por isso, Gaudemar (1977) criticou o caráter duplo da moderna liberdade do trabalhador. Por um lado, liberdade para vender onde e como quiser sua força de trabalho, o direito de ir e vir juridificado pela sociedade burguesa. Por outro, contudo, necessidade absoluta de vende-la, posto que é o único meio de reprodução daqueles que ficaram livres de tudo, de quaisquer outros meios de produção ou de sobrevivência.
} 
Revista Brasileira de História \& Ciências Sociais - RBHCS

Vol. 13 No 26, Janeiro - Junho de 2021

que organiza a escolha individual revela-se conectada a uma dimensão estrutural violenta, cujo sentido se deteriora ainda mais ante a crise da reprodução social capitalista, quando vender sua força de trabalho vai se tornando progressivamente mais difícil, devido a reiterada produção de uma população tornada supérflua ante as necessidades do capital ficcionalizado (KURZ, 2014).

Além disso, muitas pessoas que se sentem forçadas a cruzar fronteiras internacionais, nesses contextos, não se encaixam nas categorias estabelecidas no Estatuto dos Refugiados de 1951 e no Protocolo de 1967. Muitos fogem de privações de Direitos Humanos decorrente do colapso econômico e político dos seus páises de origem , como é o caso da Venezuela, justamente num momento em que derrocada econômica e política de Estados nacionais e insegurança total das populações, do ponto de vista dos Direitos Humanos, travam relação íntima. Para os ditos "migrantes voluntários", os mecanismos de proteção tornam-se imprevisíveis e inadequados. Estes migrantes têm sido, inclusive, mais propensos a serem presos, detidos e deportados do que receber algum tipo de protecão.

Entendemos, portanto, que a discriminação das migrações entre voluntárias e involuntárias pode ser arbitrária e, sobretudo, que torna-se definitivamente antidiluviana ante a crise fundamental da reprodução social capitalista. Tal categorização produz dicotomias (voluntária versus forçada, escolha versus coerção, regular versus irregular) que contém uma carga valorativa atribuindo validade a determinadas migraçõs enquanto outras são deslegitimadas. Questionamos sobretudo o fato destas dicotomias ofuscarem processos estruturais que levam os indivíduos, famílias e outras composic ões coletivas à migrarem . Isso porque, se por um lado, o processo migratório, de alguma maneira, preserva uma escolha individual, por outro, trata-se de um processo social e politico concreto que está circunscrito no sistema capitalista. Isto faz com que dinâmicas no interior desta forma social - guerras, desemprego, pobreza, destruic,ão da natureza, entre outros - impilam as pessoas a se deslocar em busca de sobrevivencia.

Tais categorizações, inclusive, são utilizadas nas políticas migratórias de modo individual, desvencilhando os migrantes das dinâmicas socioeconômicas e culturais que as impelem de migrar. E não dá conta dos atuais processos 
Revista Brasileira de História \& Ciências Sociais - RBHCS

Vol. 13 No 26, Janeiro - Junho de 2021

migratórios, cada vez mais mistos e complexos. Esse processo tem consequências negativas par a alguns grupos, em particular pessoas em fuga por questões ambientais e de pobreza. Isso porque, como afirma Robert Kurz, "frequentemente, os motivos de fuga misturam-se, quando as pessoas são atingidas simultaneamente por várias pragas apocalípitcas do sistema global capitalista" (2016, s/p).

Nesse sentido, as migrações venezuelanas nos permitem questionar a categorização dominante que acabamos de analisar uma vez que elas se inserem no complexo contexto de múltiplas crises atuais do capitalismo, onde cada vez mais a dicotomia voluntário-forçado tende ao forçado-forçado num horizonte onde as expectativas liberais se desmancham à olhos vistos.

Vejamos. A Venezuela foi historicamente considerada um país receptor de migrantes. Segundo Francilene Rodrigues (2006), o número de estrangeiros em território venezuelano na década de 1970 representava 5,5\% da populacão esta proporção foi aumentando ao longo do tempo, chegando a 7,4\% em 1980, para voltar a diminuir em 1990 (5,7\%), mas ainda refletir um número significativo. No século XXI, esse quadro foi mudando rapidamente. Paez e Penalver (2017) identificam três ondas migratórias nesse período: 1) a primeira fase é chamada de "procurando novas oportunidades" e corresponde ao período de 2000 a 2012 ; 2) a segunda fase define-se por "crescente desesperanç" e compreende o intervalo entre a morte de Chávez e o início de 2015; 3) a atual fase, nomeada pelos autores, como a "migração do desespero".

Destrinchando um pouco as ondas migratórias apresentadas por Paez e Penalver (2017), a primeira (2000-2012) é composta principalmente de famílias ou cidadãos de renda média, com alto nível educacional e profissionais instruídos que optaram por se mudar para os Estados Unidos da América ou para a Europa. Com relação à segunda onda (2013-2014), esta se relaciona com desequilíbrios mais intensos na economia venezuelana e uma tensão politica entre Nicolás Maduro e os líderes politicos que se opuseram a ele. Esse grupo de imigrantes era menos homogêneo em termos de classe e educação e, embora muitos ainda fugissem para os Estados Unidos da América e a Europa, números cada vez maiores foram para páises vizinhos.

A atual diáspora venezuelana (2015-até hoje), a "migração do desespero" (PAEZ E PENALVER, 2017), parte em conseqûencia da profunda crise 
Revista Brasileira de História \& Ciências Sociais - RBHCS

Vol. 13 No 26, Janeiro - Junho de 2021

socioeconômica na qual a Venezuela está imersa. $\mathrm{O}$ atual deslocamento forçado é muito heteroĝeneo: se expandiu para todos os grupos sociais, independentemente de renda, nível educacional ou profissão e caracterizam-se por dinâmicas mistas - isto 'é, incluem solicitantes de refúgio e os ditos migrantes econômicos. São povos indígenas, homens, mulheres, grupos LGBTQIA+, pessoas em condicão de extrema vulnerabilidade como idosos e doentes e um número cada vez maior de crianças e adolescentes desacompanhados que migram em busca de sobrevivência em diversos países do mundo. De acordo com a Plataforma de Coordenación para Refugiados y Migrantes de Venezuela (R4V), em março de 2021, 5,5 milhões de venezuelanos (as) estavam fora de seu país de origem, configurando-se como a principal dinâmica migratória na América Latina. Os principais países receptores são: Colômbia (759. 584), Peru (477. 060), Chile (472. 827), Argentina (222.658), Equador (202. 658) e Brasil (145. 462)15.

No Brasil, as migrações venezuelanas se tornaram uma pauta pública e política em 2017. Nesse período, o governo de Michel Temer elaborou uma resposta humanitária que, na verdade, se tratava de um modelo securitário de gestão dos "fluxos". Muito se discutiu entre as instituições, a academia e a sociedade civil sobre qual tipo de regularização migratória seria efetiva para tal deslocamento. Nesse mesmo ano, estabeleceu-se uma Resolução Normativa (126/ 2017) pelo Conselho Nacional de Imigração (CNIg) com o objetivo de ser uma norma de emergência que permitisse a residência temporária para aqueles que atravessassem a fronteira brasileira por via terrestre ${ }^{16}$.

Silva e Abrahão analisaram os formulários de solicitação de refúgio feitos por venezuelanos em Roraima entre 2014 e 2017. Em síntese, os dados mostram que um pequeno número de solicitações se encaixam na definição clássica do refúgio da Convenção de 1951 e grande parte dos pedidos assentam-se sobre os argumentos de crise econômica e falta de alimentos, além da grave e generalizada violação dos direitos humanos (2019, p. 266).

Além disso, nas entrevistas do trabalho de campo, os/as migrantes venezuelanos/as, frequentemente, elencaram a falta de poder de compra salarial, a falta de acesso à remédios e o interesse em trabalhar com a carteira

${ }^{15}$ Tais dados já podem estar defasados. Disponível em: https://bit.ly/2PIQFQw, acesso em: 18/03/2021.

${ }^{16}$ Disponível em: https://bit.ly/3fsWXia, acesso em: 18/03/2021. 
assinada como as principais motivações que os fizeram migrar para o Brasil. Casos como esses nos mostram que as distinções entre migração e refúgio são borradas. A fome, a vontade de trabalhar ou a busca por "uma vida melhor" para si e para os filhos se misturam. Nesse caso, essa linha entre uma categoria e outra fica cada vez mais tênue. A consequência disso é que de terminados grupos acessarão, ainda que de modo precário ou frágil, ao mundo dos direitos enquanto outros serão relegados a um sem número de vulnerabilidades não cobertas ou sequer reconhecidas por esse mundo.

Em junho de 2019, o Brasil passou a reconhecer venezuelanos/as como refugiados/as com base na "grave e generalizada violação de direitos humanos" presente na Declaração de Cartagena (1984). Nesse sentido, isso também fica nítido nas entrevistas de campo, a "escolha" pela solicitação de refúgio ou residência torna-se uma estratégica migratória por parte dos/as venezuelanos/as. A depender de cada situação, os migrantes vão optar, com algum nível de racionalidade, pela regularização que lhe permitir uma permanência legítima, independente e a despeito do que formulam as instituicọes. Além disso, como pontuam Martino e Moreira (2020) e os próprios relatos de campo, as migrações venezuelanas tem uma característica pendular, que dificulta a solicitação de refúgio, uma vez que só é possível retornar a terra natal com a permissão do país acolhedor.

Outro dado que atesta a problemática da distinção é a forma como o governo brasileiro tem concedido o status de refugiado a população venezuelana. Hoje, o Brasil é o país com maior número de refugiados venezuelanos reconhecidos na América Latina. De acordo com R4V, aproxidamente 46 mil venezuelanos estão reconhecidos em território brasileiro. Isso só foi possível pela utilização da prima facie adotado pelo Comitê Nacional para Refugiados (CONARE). Isto é, o cruzamento de dados através do uso de inteligência artificial. Tal recurso é considerado, pelas organizações internacionais, um avanço na proteção de refugiados por agilizar a análise dos pedidos. O tempo médio para um pedido ser processado pelo CONARE é de dois a três anos ${ }^{17}$. O Alto-comissariado das Nações Unidas para os Refugiados (ACNUR) elogia o interesse do Brasil em agilizar os pedidos para o status de

${ }_{17}$ Disponível em: https://bit.ly/3fpRFUA, acesso em: 18/o3/2021. 
refugiado. Esta perspectiva se reflete também na mídia brasileira, reforçando um velho mito de páis acolhedor, cordial e paraíso da democracia racial.

Em suma, esse breve panorama sobre as migrações venezuelanas e como o Estado brasileiro se relaciona com as mesmas aponta para algumas problemáticas fundamentais presentes nesse processo. Primeiro, no tocante aquela ideologia liberal que falamos no início. Os valores liberais em torno da mobilidade fundamentam toda uma gramática do positivismo jurídico que, mais do que nunca, se desvela como uma ideologia de exclusão. Como argumentamos até aqui, os deslocamentos contemporâneos - tanto os ditos voluntários quanto os involuntários - surgem de um ponto comum, a saber, a crise fundamental da reprodução social capitalista e suas múltiplas expressões, que produz permanentemente massas de seres humanos considerados supérfluos e que se veem impelidos a migrar não só na Venezuela, mas em uma infinidade de outras localidades.

Essas dicotomias (voluntários versus forçados) servem, sobretudo, para qualificar quais grupos e quais pessoas podem adentrar o território e sob que circunstâncias, o que significa, na prática, que um pequeno número de pessoas terá acesso sempre precário ao mundo dos direitos enquanto a maioria permanecerá em um processo de contínua exclusão, distribuído desigualmente segundo o corte racista e patriarcal que modula a socialização capitalista. Por fim, essa crise das distinções entre um e outro evidencia como a forma jurídica não se pretende mais um "antídoto" para a violência e para a arbitrariedade, mas torna-se parte constituinte dessa relação. A militarização, nesse sentido, é a expressão máxima desse processo.

\section{Crise da reprodução social capitalista e militarização}

Todo o bolivarianismo fora marcado pela intensa presença militar. O exército foi responsável, para darmos apenas um exemplo, pelo Plano Bolívar 200, a primeira política social do período, e membros das forças armadas, da ativa ou reformados, passaram a dirigir ministérios, governos estaduais e municipais (UZCÁTEGUI, 2020). Não obstante isso, o governo Maduro tem sido capaz de aprofundar o quadro. Em 2014, acompanhando a agudização da crise, ocorreu a criação da Brigada Especial contra Atuações dos Grupos Geradores de Violência (BEGV), a integração dos militares nas operações para 
reprimir protestos contra o governo, uma decisão judicial que autorizou a participação das forças armadas em atos político-partidários e a promulgação de uma nova lei de alistamento militar ${ }^{18}$. Além disso, incentivou-se vigilância e delação por parte de civis "patriotas cooperativos", revelando o engajamento de toda a sociedade no processo (ROMERO-CASTILLO, 2014).

Na tentativa de contornar os efeitos da crise, os esforços de atração do capital transnacional e da mobilização de novas rodadas de crédito, amplificaram as pressões extrativistas e a militarização. Em 2016, Maduro decretou a criação da Zona de Desenvolvimento Estratégico Nacional Arco Minero do Orinoco, com alcance de cerca de $12 \%$ do território nacional, para estimular investimentos estrangeiros em mineração de grande escala, mediante incentivos fiscais e flexibilização de legislação trabalhista, ambiental e de proteção dos povos indígenas ${ }^{19}$. Um papel central nesse projeto foi atribuído para as forças armadas, responsável pela repressão de quaisquer formas de resistência e pela criação de empresas mineradoras sob sua responsabilidade direta (LANDER, 2017).

Ao fim de 2017, 34\% dos integrantes do gabinete presidencial já eram militares, o Ministério da Defesa havia recebido autonomia administrativa e empresarial e a criação de empresas militares ganha ainda mais força. Além disso, as forças armadas assumiriam o comando irrestrito da importação e distribuição de alimentos, dos registros de divisas subsidiadas, dos portos, do controle da mineração ilegal, da vigilância das fronteiras, etc., setores que contam todos eles com inúmeras denúncias de corrupção (LANDER, 2017).

Olhar para o problema da militarização exigiria ainda uma consideração sobre as relações econômicas da Venezuela com a Rússia, a China, os EUA, muitas delas com repercussão militar. O país foi o líder sul-americano na importação de equipamentos bélicos entre 2003 e 2007 e a Rússia foi seu maior fornecedor ${ }^{20}$. Poder-se-ia dizer que também foi importado da Rússia o modelo

\footnotetext{
${ }^{18}$ A constituição de 1999 deu para os militares direito ao voto, mas não à manifestação políticopartidária.

${ }^{19}$ Esse território já vinha sofrendo as consequências da expansão do garimpo ilegal nos últimos vinte anos, com relatos da chegada de dezenas de milhares de garimpeiros, controle do território por máfias, tráfico de drogas e trabalho degradante generalizado, com a participação de autoridades regionais e corpos de segurança do Estado, em tese responsáveis por impedir a realização de tais atividades (LANDER, 2017).

${ }^{20}$ A aproximação se intensifica quando os EUA certificam a Venezuela como not cooperating fully com a luta antiterrorista americana, mediante a Section A of the Amrs and Control Act,
} 
de controle energético venezuelano. Antes de Chávez, Putin promoveria reestatização parcial do setor de petróleo e gás e controle estratégico daquela indústria. Contraditoriamente, contudo, e inclusive devido a vultuosos empréstimos para compra de armamentos feitos pela Venezuela ${ }^{21}$ a Rússia passaria a se apropriar de forma progressiva e intensificada pela crise dos ativos da PDVSA dados como garantia para a obtenção dos créditos, sobretudo os do exterior $^{22}$. Ademais, talvez seja esse um dos interesses centrais da Rússia em seus negócios com o país: viabilizar sua presença no mercado energético de países ocidentais (BARROS; PINTO, 2012; IPEA, 2019; TRIPATHI; SB, 2020).

Uma análise das relações com a China igualmente apontaria uma conexão entre exportação de petróleo, endividamento e importação de equipamentos bélicos ${ }^{23}$. Para além da sua importância na dinâmica de militarização venezuelana, ela revelaria, ademais, a impossibilidade de a exportação de matérias-primas garantir qualquer aparente ciclo de desenvolvimento capaz de recolocar, de fato, mercantil e geopoliticamente a posição de um Estado na corrida global. Com a crise, portanto, apesar das ameaças de intervenção militar estrategicamente propaladas pelos EUA e a presença de aliados esses, sim, relevantes geopoliticamente, que também se posicionam no cenário (LISSARDY, 2019), o poderio adquirido pela Venezuela

embargando venda, financiamento ou assistência militar ao país (VILLA, 2008). Um episódio conhecido no Brasil foi a proibição pelos EUA de que a Embraer vendesse 25 aviões brasileiros Super Tucanos para o país em 2006, por conter componentes americanos.

${ }^{21}$ Após 2005, a Venezuela comprou da Rússia 100 mil fuzis AK 47, caças, submarinos, misseis de terra e de longo alcance, helicópteros de combate e de transporte, tanques, etc., quase sempre por meio da concessão de créditos, que, só em 2009, foi da ordem dos US\$ 2,2 bilhões e estimase que tenha alcançado o montante de 17 bilhões. Além disso, Chávez promoveria a integração entre os dois exércitos mediante exercícios conjuntos, liberação do território nacional para exercícios russos e instalação de fábricas de armamentos (BARROS; PINTO, 2012).

${ }_{22}$ Por meio do Consórcio Nacional Petroleiro (Lukoil, Rosneft, Gazprom, TNK-BP e Surguntneftegaz), a Rússia realizaria inúmeros convênios com a PDVSA, criando empresas mistas e comprando o direito de exploração em campos venezuelanos. Com a crise e sobretudo com as sanções, a Gazprom deixa o território venezuelano para não sofrer embargos pois é uma importante fornecedora de gás para a Europa, especialmente Alemanha, enquanto a Rosneft aumenta muito sua participação nos ativos da PDVSA fora da Venezuela, como, por exemplo, nos EUA, onde comprou 49,9\% das ações da subsidiária Citgo, com sete mil postos de gasolina na Costa Leste em 2016. (BARROS; PINTO, 2012; IPEA, 2019; TRIPATHI; SB, 2020).

${ }^{23}$ A China, por sua vez, também se torna parceira importante na exportação de equipamentos bélicos para a Venezuela apenas após 2005. Daí em diante, contudo, 90\% das suas vendas para a América Latina serão para o país. O endividamento venezuelano com a China também é o mais expressivo do continente: $40 \%$ dos US $\$ 155$ bilhões emprestados pelo país para a América Latina e o Caribe nos últimos 20 anos foram para a Venezuela (LIY, 2019). Parte importante desse endividamento seria custeado por exportação de petróleo e acabaria empregado na produção de infraestrutura, inclusive para assegurar o abastecimento do mercado interno chinês com combustível e especialmente as tropas navais civis e militar (BARROS; PINTO, 2012). 
parece repercutir cada vez mais internamente na gestão ultra repressiva da falência das condições de reprodução social no país, culminando em uso desmedido da força, mortes, tortura, prisões arbitrárias, etc. (AI, 2019).

A ameaça de que o Brasil possa virar a Venezuela, mobilizada à exaustão desde a campanha presidencial de Jair Bolsonaro e até bastante recentemente, sobretudo para justificar as perspectivas presidenciais de arrocho fiscal (SARDINHA, 2021) só ganha mesmo verossimilhança quando o assunto é militarizaçãó24. Desde 1989, não ocorriam eleições abertamente tuteladas pela ameaça de sublevação dos quartéis, caso o resultado não correspondesse ao esperado por uma ala do exército brasileiro, conforme as exaustivas declarações aos meios de comunicação, em 2018. Não à toa, àquela ala corresponderiam à quadros com participação de destaque na Missão das Nações Unidas para a Estabilização no Haiti (MINUSTAH) e na Intervenção Militar Federal no Rio de Janeiro em 2018. O atual ministro do Gabinete de Segurança Institucional, general Augusto Heleno, já em 2003 avisava que a missão proporcionaria um treino a ser replicado nos morros cariocas (MENEGAT, 2019).

As justificativas para a ação da MINUSTAH interessam para pensar o contexto mais geral da militarização em curso. Os argumentos da resolução da ONU apontavam uma generalizada falência estatal e seus efeitos para a estabilidade da região, inclusive devido a possíveis dinâmicas migratórias para outros países, além da necessidade de resposta ao processo interno de dissolução social que culminara em descontrole de criminalidade e violência. A situação em que se encontrava o Haiti não tardaria, entretanto, a espalhar-se pela América Latina e pelo mundo, o que dá especial interesse ao exemplo, com a situação venezuelana ganhando centralidade na catástrofe global (MENEGAT, 2019).

Com a crise de 2008 e o estouro da bolha das commodities, a qual havia proporcionado em contextos territoriais específicos uma gestão da barbárie como aquela levada a cabo pelos governos petistas no Brasil, as democracias do mundo inteiro entram em um colapso de legitimidade, reconhecido até mesmo pela literatura liberal (MENEGAT, 2019). O agravamento da crise capitalista exige do Estado que se volte exclusivamente para manter promessas de

${ }^{24}$ Essa tônica, inclusive, já estava presente desde a referida campanha: "Agora é guerra!!! Ou é agora ou vira Venezuela!!!” fora o ultimato que servia à mobilização para as fileiras bolsonaristas (CHAGAS et al. 2019). 
acumulação, apesar de curtas e restritas, independente dos custos sociais e ambientais que isso tenha que acarretar, o que assinala a derrocada que qualquer caráter civilizatório que a sociedade burguesa pretendera ter. Conforma-se uma guerra sem guerra marcada pela generalização do estado de exceção e uma economia de guerra permanente, alimentada aqui e ali por bolhas financeiras, cuja função não é mais expansionista, mas securitária, ou seja, de proteção dos enclaves em que a reprodução do capital ainda parece possível contra as populações que avançam dos territórios em dissolução (KURZ, 2016).

Nessa chave, torna-se evidente o sentido da Força Tarefa Logística Humanitária ou Operação Acolhida (OPA) como iniciativa central do Brasil ante a crise da Venezuela e importante elo na escalada da militarização nacional como forma de gestão da crise internamente ${ }^{25}$. Para além de qualquer expectativa de participação brasileira em eventual intervenção no território venezuelano, a atual concertação geopolítica já atribuiu ao país responsabilidade na gestão de conflitos que se externalizam na fronteira e salvaguarda da estabilidade regional, com evidente prioridade para o controle migratório e de seus impactos. Os pilares de atuação da OPA centram-se, assim, no abrigamento, na interiorização e no ordenamento de fronteira, incluindo ações para otimizar a distribuição do contingente de migrantes no território nacional e regular a sobrecarga dos serviços públicos brasileiros, enquanto também se admite a necessidade de controlar a proliferação de atos criminosos supostamente provocados por migrantes ou facilitados pelo contexto das migrações e até mesmo o intercâmbio e a transferência de organizações criminosas (RAMALHO, 2019).

Estudiosos tem apontado a contradição entre humanitarismo e securitização na abordagem do governo federal para o problema (MENDONÇA, 2018a) e uma espécie de militarização da assistência social pela operação (PAIVA, 2020). A questão não se refere somente ao acolhimento ser

\footnotetext{
${ }^{25}$ Não é sem importância que a OPA tenha se iniciado sob o comando de Eduardo Pazuello, general que deixara recentemente o Ministério da Saúde em plena crise sanitária no provocada pela pandemia de Covid-19 como suspeito por omissão no colapso da rede pública entre outras atribuições da pasta (RODRIGUES, 2021). Nem que Antonio Manoel de Barros, general que assumiu o comando da OPA no seu lugar, tenha sido responsável por ordenar a desastrosa e repleta de irregularidades Operação Muquiço, que levou a morte três pessoas após um carro considerado suspeito ter sido alvejado por 62 tiros (VIANA, 2020).
} 
efetivamente feito por militares, mas também à relação de necessidade que se põe entre o acesso à proteção nos abrigos e outros equipamentos e a exigência de regularização migratória ou ao tipo de triagem que permite a interiorização. Argumenta-se, todavia, que a aproximação entre migração e criminalidade, por um lado, e humanitarismo e securitização, por outro, se tornara constitutiva de um regime global de controle das migrações em uma conjuntura de criação acelerada de contingentes de despossuídos em deslocamento pela crise capitalista. A apologia de uma migração segura, ordenada ou a mixórdia de noções como acolhimento, proteção social, controle migratório, migração como problema ou migrante irregular e ilegal na teoria e na prática do campo migratório são sinais do processo. Promove-se, com isso, a mobilidade dos "desejáveis" enquanto migrantes indocumentados, profissionais do sexo, pessoas negras, pobres, etc. são evitadas com recurso à sua criminalização (FELDMAN-BIANCO, 2018).

No âmbito da OPA, essa dinâmica transborda a triagem de fronteira, definindo o acolhimento nos campos de refugiados chamados no Brasil de abrigos humanitários, supostamente diferenciados por integrarem o espaço urbano e permitirem a circulação dos migrantes pelas cidades. Contudo, mantém-se sua forma e sentido de depósito murado e ordenado de pessoas cartesianamente distribuídas nas unidades de alojamento, cujo acesso à alimentação se garante em filas de distribuição de marmitas, onde entrada e saída são controladas bem como todas as outras atividades, podendo as infrações inclusive levar a advertências ou desligamento dos chamados usuários ${ }^{26}$ (PAIVA, 2020).

Para além da dimensão arquitetônica dos campos e o que ela revela, o controle em questão refere-se à própria condição do migrante, constantemente sujeita à suspensão das garantias mediante as quais ele é tolerado. No âmbito do campo, a possibilidade de ser considerado infrator apenas repercute a possibilidade de criminalização que já organiza a mobilidade dos indesejáveis. Justifica o processo tratarem-se de invasões bárbaras. Historicamente, o estado de exceção se territorializou como regra nas colônias, o além-fronteiras da

${ }^{26}$ Barracas do exército brasileiro ou casas desmontáveis da ONU, totalmente inadequadas para o clima amazônico, espalham-se sobre um terreno nivelado e coberto com brita, rodeadas por iluminação vigilante e placas que estabelecem regras de convivência com relação a barulho, higiene, circulação, etc. 
civilização europeia em cujos territórios se consolidou o estado de direito, dependente, vinculado de forma necessária, a saque e dilapidação colonial (MBEMBE, 2018).

Com a crise, a legitimidade para o exercício da barbárie colonial, que nunca desaparecera no curso da modernização capitalista, se aprofunda. Acontece que agora os bárbaros é que se movem daqueles territórios alémfronteiras, porque qualquer promessa civilizatória que um dia reproduziu sua territorialização entra em completa ruína. O expansionismo colonialista atualiza-se na proteção securitária contra os deslocados despossuídos, tidos como hordas que avançam tal qual o retorno do reprimido (KURZ, 2016). Por isso é necessário atacar frontalmente a ideia de uma crise migratória, revelando os fundamentos de uma crise da reprodução capitalista, que os Estados buscam gerir se militarizando para sustentar o pressuposto alargamento do estado de exceção.

Como o movimento expansionista foi suplantado pela proteção contra as invasões bárbaras, que se reproduzem mesmo sem muros, cercas, cães ou pistolas para barrar os migrantes, a territorialização sempre além-fronteiras tem de se internalizar porque o outro construído como ameaça (terrorista, criminoso, migrante) agora está em meio às ilhas de civilização que tem que se apoiar sobre montanhas de náufragos para não afundar. Torna-se necessário limitá-lo a territórios definidos exatamente pela possibilidade da supressão de garantias. O confinamento passa a ser a forma de existência do estado de exceção e galga posições como padrão territorial da crise da reprodução social capitalista (LEITE et al. 2020).

\section{Experiências venezuelanas em Roraima: uma necropolíticas da fronteira}

Uma análise sobre as experiências migrantes em Roraima precisa partir desse diagnóstico do confinamento como política privilegiada para lidar com os corpos migrantes e pela "pertença excluída" aos quais são submetidos. Esse reconhecimento parece apontar para o que Mbembe (2018) tem chamado de necropolítica. Nesta importante obra, o autor argumenta que a "expressão máxima da soberania reside, em grande medida, no poder e na capacidade de ditar quem pode viver e quem deve morrer" (MBEMBE, 2018, p. 5). 
O pensador camaronês ocupa-se, sobretudo, sobre as formas de soberania onde há uma "instrumentalização generalizada da existência humanae a destruição material de corpos humanos e populações" como projeto primordial. Neste contexto, os campos de morte tornam-se o "nomos do espaço político em que vivemos" (MBEMBE, 2018, p. 10-11). O poder, por sua vez, se manifesta pelo apelo "à exceção, à emergência e a noção ficcional do inimigo" (MBEMBE, 2018, p. 16).

As tecnologias necropolíticas, diz o autor, são aquelas técnicas de aplicação da morte, como o campo de concentração ou, para fins desta pesquisa, além do confinamento, as outras muitas condições de morte-em-vida que os migrantes venezuelanos são submetidos no Brasil, que não apenas disciplinam, mas sujeitam os corpos à destruição física e subjetiva total. Trata-se da capacidade de definir "quem importa e quem não importa, quem é descartável e quem não é" (MBEMBE, 2018, p. 41). O controle sobre a mortalidade e a definição da vida representam as manifestações de poder do soberano.

Essa imagem-pensamento nos parece muito fértil para entender os processos de fortificação de fronteiras e detenção de migrantes e refugiados em campos de confinamento. Em se tratando de Brasil, entendemos a Operação Acolhida como a necropolítica da fronteira por ser a afirmação do controle físico, geográfico e simbólico, cujo sentido é uma nova territorialização do espaço e dos corpos (CASTRO, 2020). Esse movimento produz continuamente hierarquias e novas fronteiras. Nessa configuração, a violência torna-se "a forma original do direito" e a exceção viabiliza a "estrutura da soberania" (MBEMBE, 2018, p. 38). Toda essa forma de fragmentação do espaço baseia-se sempre numa relação entre classe, gênero e principalmente raça.

Nas pesquisas de campo, nos deparamos com os diversos modos de regulação dos migrantes que funcionam com base na multiplicação de situações aparentemente intoleráveis e muitas vezes absurdas: a arquitetura dos abrigos e sua produção de uma condição mínima de vida, a falta de autonomia dos/as migrantes, a xenofobia e o racismo, as pequenas violências cotidianas que quase passam despercebidas, os processos de despejo e desocupações das ocupações espontâneas em plena pandemia. Os problemáticos caminhos de "integração" dos migrantes venezuelanos à sociedade brasileira não se encerram na Operação Acolhida. 
Há, por um lado, xenofobia institucional que se desvela nas tentativas de fechamento da fronteira, como o orquestrado pela então governadora Suely Campos em agosto de 2018 (NUNES, 2018), no discurso anti-imigração como proposta de campanha, adotada, por exemplo, pelo deputado federal Nicoletti (PSL) candidato à prefeitura de Boa Vista em 2020 (ZANINI, 2020), entre outros.

E, por outro lado, a capilarização dessa narrativa por parte da população roraimense. Durante todo o trabalho de campo foi comum escutar os brasileiros reclamando sobre o descontrole dos "fluxos" migratórios e culpabilizando os venezuelanos pelos problemas de saúde, emprego e segurança no estado de Roraima. A expressão máxima dessa dimensão xenofóbica são os ataques e linchamentos à imigrantes, que já chegaram a impactar o ritmo de entrada de pessoas no Brasil, sobretudo diante da organização de "patrulhas de controle", com direito a toque de recolher na fronteira com Pacaraima (MENDONÇA, 2018b). No campo, um relato ilustra essa situação:

\begin{abstract}
Há muitas coisas que os brasileiros fazem conosco que nós ignoramos. Estamos aqui por necessidade, muitos de nós não vieram para cá de férias, estamos tristes por estarmos aqui. Tínhamos nossa casa, nossa vida, nosso trabalho. E eu tenho escutado na televisão e no rádio pessoas que falam sobre os venezuelanos. Tem um jornalista brasileiro que tem chamado os venezuelanos de vagabundos. Mas tudo que temos visto aqui no acampamento, como uns 97\%, pensam em trabalhar, vieram pela loucura que está acontecendo na Venezuela. Eu vejo pessoas aqui saindo 5 da manhã atrás de trabalho, procurando trabalho, assim é com meu esposo, assim é com meus vizinhos. Não é justo o que eles falam dos venezuelanos como se fossemos todos iguais. Há muitos que estão fazendo ou podem ter feito mal, e a esses os brasileiros dedicam 1 hora do programa para falar mal. No entanto, um venezuelano foi atropelado há pouco tempo por um brasileiro, com o seu filho, que quase caiu morto, e somente falaram sobre isso alguns segundos. Mas quando o venezuelano faz algum mal a alguém é uma hora dedicado à "fora os venezuelanos!". Te asseguro que no momento que a Venezuela melhorar, nós vamos embora daqui (Venezuelana, ocupante de Ka Ubanoko em relato de campo).
\end{abstract}

Há ainda uma outra dimensa o que se soma à necropolitica da fronteira como um processo de violência cotidiano enfrentado pelas mulheres $\mathrm{m}$ igrantes: o assédio . Em muitas conversas esse aspecto veio à tona e tem relação com um dos principais meios de sobrevivência acessado pelas mulheres, a saber, a prostituição. Concentradas no bairro do Caimbé, em Boa Vista, as mulheres venezuelanas em situação de prostituição foram pejorativamente apelidadas como "ochentas", em referência ao valor cobrado pelo programa (MENEZES; ESTRELA 2019). Com frequencia, as migrantes são chamadas de "ochentas" ou 
"venecas" como uma forma de insulto.

Em 2016, nove venezuelanas foram resgatadas após serem mantidas sob cárcere privado e obrigadas a se prostituir em troca de comida e acomodação. Todo o dinheiro que ganhavam era repassado para um brasileiro responsável pela casa (MENEZES; ESTRELA 2019). Em 2019, a Policia Civil fez um levantamento que registrou o aumento, em mais de $30 \%$, de casos relacionados a tráfico de mulheres na fronteira brasileira. Inclusive, assumem que os números são, na verdade, bem maiores. De acordo com os boletins de ocorrência registrados nos últimos três anos, mais de 50\% das vítimas de tráficos eram venezuelanas (CORREIA, 2019).

Marcia Oliveira (2014) nos conta que o imaginário popular na Amazônia se construiu na naturalização desse tipo de violência contra as mulheres e na percepção da mulher amazônica como excessivamente sensual, exótica e permissiva à prostituição. A autora observa uma intensificação do processo migratório na região amazônica, em especial de dinâmicas cada vez mais feminizadas e com isso também o aumento do tráfico de mulheres e prostituição na região. E que recentemente parece ganhar novas configurações com as migrações venezuelanas.

Esse quadro demostra que os modos de vida da população venezuelana em território brasileiro, e para fins desta pesquisa, no estado de Roraima, os submetem a condições de sobrevida tal qual postulado por Achille Mbembe. Por esta ótica, os imigrantes precisam reproduzir sua existência de alguma maneira. A esta população, em grande medida, sobra essas formas de ocupação perigosas e ilegais, tal qual o garimpo e o crime organizado.

A questão do garimpo ilegal avança no Brasil. Em Roraima, a maior parte se concentra nas terras indígenas Yanomami, onde existe uma estimativa da Funai de um número entre 7 a 10 mil garimpeiros trabalhando (COSTA; OLIVEIRA, 2019). Esse ponto nos interessa porque, como afirmamos, existem indícios de venezuelanos atuando de modo irregular na extração de minérios na região. Assim como tem sido recrutrados pelo PCC para assumir cargos de confiança (ALESSI, 2021). Essas duas dimensões parecem demonstrar um estreitamento das relações entre o crime organizado nos dois países e que tem a população venezuelana como alvo pela precariedade em que vivem tanto na Venezuela como no Brasil (ZUKER, 2018). 
Quando não encerrados em espaços de confinamento como os abrigos da Operação Acolhida ou empenhados em trabalhos ilícitos, sobram aos venezuelanos poucas opções. No cotidiano do campo, encontramos vários venezuelanos se dividindo entre as poucas diárias. Para os homens, em geral, trata-se do trabalho de carpinteiro, capinador ou recolher ferro e outros mateiriais pela cidade. As mulheres, por sua vez, ocupam as tarefas domésticas ou no cuidado de crianças brasileiras. Há também relatos de experiência na área da cozinha, costura e manualidades. Todos esses trabalhos muito mal remunerados e insuficientes para o sustento de uma família inteira. Além disso, é comum ouvir histórias de exploração e ameaças por parte dos patrões, na maioria das vezes, brasileiros. Uma dimensão que aparece como uma alternativa de sobrevivência e que é, inclusive, estimulado pelas instituições da Operação Acolhida é o empreendedorismo. Por toda a cidade é possível encontrar venezuelanos/as vendendo comidas típicas, lanches, roupas, artesanato, etc.

Além dos trabalhos, as e os migrantes venezuelanos buscam estratégias de sobrevivência, por fora da Operação Acolhida, nas ocupações espontâneas. Em meados de 2019, o número desse tipo de ocupação crescia em Boa Vista e mais de mil venezuelanos ocupavam prédios públicos e privados abandonados como uma alternativa a vida nos abrigos (COSTA, 2019): Antiga Secretaria de Educação, Totozão, Segad, Antiga Creche, Futura PM, Clínica de Reabilitação, Antigo Shopping, Casa Bernardo Coutinho, Embratel e Clube do Trabalhador, nomeada de Ocupação Ka Ubanoko.

Em 27 de fevereiro, a Operação Acolhida apresenta o "Plano Emergencial para Ocupações Espontâneas (OEs)” para a realocação dos migrantes que viviam em onze ocupações. Três ocupações foram listadas para serem evacuadas o mais rápido possível devido às más condições estruturais do prédio: SEGAD, o Antigo shopping de Boa Vista e a Secretaria de Educação. Apesar da pandemia de COVID-19 ter sido decretada em 11 de março de 2020 pela Organização Mundial da Saúde (OMS), as desocupações continuaram. Entre março e setembro, sete ocupações espontâneas, com um total de quase 1.300 pessoas, foram desalojadas (FOLHA WEB, 2020). Em setembro, Ka Ubanoko recebeu a notícia de despejo com a data limite para desocupação em 28 de outubro. Mesmo com a mobilização das lideranças com a sociedade civil, a ocupação foi 
Revista Brasileira de História \& Ciências Sociais - RBHCS

Vol. 13 No 26, Janeiro - Junho de 2021

totalmente desfeita em janeiro de 2021.

Esse breve panorama sobre as condições de "integração" dos migrantes venezuelanos em território brasileiro parece confirmar a nossa hipótese de uma necropolítica da fronteira e um circuito permanente de "inclusão excluidora e exclusão inclusiva" como bem define Kurz (2016). Esses diversos mecanismos necropolíticos vão sendo acionados constantemente com o intuito de gerir condições de sobrevida às populações migrantes, mesmo quando camufladas por uma retórica de "acolhimento" como é o caso da Operação Acolhida. Esse necropoder está inteiramente ligado à crise de reprodução da sociedade capitalista, na qual a sociedade brasileira também está inserida.

Nesse cenário, a condição de supérfluo se aprofunda e a forma de inclusão na sociedade brasileira só pode ser pelo meio da exclusão, demonstrando “o fim absoluto da „cidadania' moderna” (KURZ, 2016, s/p). Essa condição paradoxal, cujo migrante é integrado e excluído mutuamente, "trata-se da 'integração na cidadania' de mortos-vivos, de sujeitos dessubjectivados. A dependência salarial dissolve-se de modo meramente formal no 'autoempresariado' que, no entanto, revela ser um empresariado de miséria" (KURZ, 2016, s/p).

\section{Considerações Finais}

Neste artigo procuramos discutir as recentes migrações venezuelanas para o Brasil em sua relação com a crise da reprodução social capitalista. Entendemos que o processo de deterioração das condições de vida e a escalada autoritária na Venezuela são, assim como os próprios processos migratórios, expressões de um cenário mais complexo: o colapso do capitalismo, altamente ficcionalizado, que já não consegue encontrar meios para se sustentar, sobretudo após o crash de 2008. Quando olhamos para a América Latina, a República Bolivariana mostra-se exemplar para entender as múltiplas crises atuais. Diante deste diagnóstico, as categorias entre migração voluntária e forçada, tornam-se cada vez mais insuficientes diante dos deslocamentos atuais. Além disso, produzimos uma reflexão crítica sobre a atuação da Operação Acolhida, criada para gerir a população venezuelana como um problema de segurança nacional e utilizando, por este motivo, o confinamento como padrão territorial de gestão de crise. Por fim, com base nos trabalhos de campo e da 
Revista Brasileira de História \& Ciências Sociais - RBHCS

Vol. 13 No 26, Janeiro - Junho de 2021

investigação bibliográfica e jornalística, postulamos que as experiências venezuelanas em Roraima devem ser entendidas enquanto uma necropolítica da fronteira, cujo sentido é submete-los a condições de sobrevida e de criar as circunstâncias da morte.

\section{Bibliografia}

ALESSI, Gil. Venezuelanos ganham força e cargos-chave no PCC em Roraima após "batismo" feito por liderança nacional, El país, Primeiro Comando da Capital, 2021. Disponível em: https://bit.ly/3ftClGC, acesso em: 18/03/2021.

AI. Anistia Internacional. O estado dos direitos humanos no mundo. Informe 2017/2018. 2019. Disponível em: https://bit.ly/3tYzbOZ, acesso em: 18/03/2021.

BARROS, Pedro Silva. O governo Chávez e desenvolvimento: a política em processo. Dissertação (Mestrado), Pontifícia Universidade Católica - PUC, São Paulo, SP, 2007.

; PINTO, Luiz Fernando Sanná. A presença dos países do BRICS na Venezuela. Boletim de Economia e Política Internacional IPEA, n. 9, p. 101-115, 2012.

BELLUZZO, Luiz Gonzaga. O capital e suas metamorfoses. Campinas: Ed. UNESP, 2012.

CELAG. Centro Estratégico Latino-Americano de Geopolítica. Las consecuencias económicas del boicot a Venezuela. 2019. Disponível em: https://bit.ly/38ZZfBA, acesso em: 18/03/2021.

CHAGAS, Viktor; MICHELLE, Modesto; DANDARA, Magalhães. O Brasil vai virar Venezuela: medo, memes e enquadramentos emocionais no WhatsApp pró-Bolsonaro. Esferas, n. 14, p. 1-17, 2019.

CORREIA, Cyneida. Migrações de venezuelanas aumenta tráfico de mulheres na fronteira com o Brasil. Estado de São Paulo, Internacional. 2019. Disponível em: https://bit.ly/3fowzGh, acesso em: 18/03/2021.

COSTA, Emily. Ocupações crescem e mais de 1,3 mil venezuelanos vivem em prédios abandonados em Roraima. G1, Roraima, 2019. Disponível em: https://glo.bo/3u80kxy, acesso em: 18/o3/2021.

; OLIVEIRA, Valéria. Sem nenhum garimpo legal, RR exportou $771 \mathrm{~kg}$ de ouro em 3 anos; vendas dobraram nos últimos 2 meses. G1, Roraima, 2019. Disponível em: https://glo.bo/3u7oOJo, acesso em: 18/03/2021.

D" ERIZANS, Ricardo Guanipa. Crise econômica venezuelana: resultado de décadas de má gestão. Diálogo: Revista Militar Digital, 2019. Disponível em: https://bit.ly/3vOxoPO, acesso em: 18/03/2021.

FELDMAN-BIANCO, Bela. O Brasil frente ao regime global de controle das migrações: Direitos humanos, securitização e violências. Travessia, n. 83, p. 11-36, 2018.

FOLHA WEB. Quase 1.300 imigrantes foram retirados de ocupações 
espontâneas. Folha BV, Operação Acolhida, 2020. Disponível em: https://bit.ly/3frH8sf, acesso em: 18/03/2021.

FRANKLIN, Cleber Batalha. A crise na Venezuela e os desdobramentos para o Brasil. XVI Congresso Internacional FoMerco, UFBA, Salvador, 2017.

HAUSMANN, Ricardo. Intervenção militar estrangeira na Venezuela deve ser considerada. Folha de São Paulo, 2018. Disponível em: https://bit.ly/3s86XAO, acesso em: 18/o3/2021.

IPEA. Instituto de Pesquisa Econômica Aplicada. BRICS Academic Forum. 2019. Disponível em: https://bit.ly/3csDYlZ, acesso em: 18/03/2021.

KURZ, Robert. Imperialismo de exclusão e estado de excepção. Exit!, n. 13, p. 123-169, 2016. Disponível em: https://bit.ly/3dgc23P, acesso em: 18/03/2021.

. Dinheiro sem valor. Lisboa: Ed. Antígona, 2014.

LEITE, Ana Carolina Gonçalves; GIAVAROTTI, Daniel Manzione. Padrão territorial e crise do trabalho: o confinamento como forma de territorialização das relações sociais capitalistas contemporâneas. Cuadernos de Geografía, v. 20, p. 32-50, 2020.

LISSARDY, Gerardo. Os EUA podem realmente invadir a Venezuela? BBC News, Mundo, 2019. Disponível em: https://bbc.in/3u2UIgy, acesso em: 18/03/2021.

LIY, Macarena. China e Venezuela: uma relação baseada em dívidas. El País, Internacional, 2019. Disponível em: https://bit.ly/3rtcIZo, acesso em: 18/03/2021.

MBEMBE, Achille. Necropolítica. São Paulo: N-1 edições, 2018.

MENDONÇA, Heloísa. Com 40.ooo venezuelanos em Roraima, Brasil acorda para sua "crise de refugiados", El País, 2018a. Disponível em: https://bit.ly/3svBnol, acesso em: 18/03/2021.

. O "monstro da xenofobia" ronda a porta de entrada de venezuelanos no Brasil, El País, Êxodo Venezuelano, 2018b. Disponível em: https://bit.ly/3rCWpIS, acesso em: 18/03/2021.

MENEZES, Leilane; ESTRELA, Igor. Órfãs de terra-mãe. A saga das mulheres venezuelanas refugiadas no Brasil. Metrópoles, 2018. Disponível em: https://bit.ly/3fwnoFd, acesso em 25/03/2021.

NUNES, Juliana Cézar. Governadora de Roraima determina controle da fronteira venezuelana. Agência Brasil, Política, 2018. Disponível em: https://bit.ly/3mcLcOf, acesso em 25/03/2021.

PAIVA, Ariane Rego de. Operação Acolhida entre a militarização e a assistência social. $8^{\circ}$ Encontro Internacional de Política Social, Vitória, Espírito Santo, 2020.

PAIVA, Rafael Bianchini Abreu. A tragédia econômica venezuelana. Carta Capital, Conjunturando, 2017. Disponível em: https://bit.ly/3lCiLJk, acesso em: 18/03/2021.

PAULANI, Leda. Não há saída sem a reversão da financeirização. Estudos Avançados, v. 31, p. 29-35, 2017. 
PITTA, Fábio; LEITE, Ana Carolina Gonçalves; KLUCK, Erick. O boom e o estouro da bolha das commodities no século XXI e a agroindústria canavieira brasileira: da mobilização à crise do trabalho. Revista NERA, v. 23, p. 41-63, 2020.

RAMALHO, Sérgio. Maior facção da Venezuela tem núcleo em solo brasileiro agindo em Roraima. UOL, Segurança Pública, 2019. Disponível em: https://bit.ly/3dgug.5k, acesso em: 18/03/2021.

RODRIGUES, Thais. Sem foro, Pazuello passa a ser julgado pela Justiça Federal de Brasília. Congresso em foco, 2021. Disponível em: https://bit.ly/3ctlthp, acesso em: 18/03/2021.

ROMERO-CASTILlO, Evan. Militarização avança na Venezuela. Deutsche Welle, América Latina, 2014. Disponível em: https://bit.ly/3daKH3o, acesso em: 18/03/2021.

SANTOS, Fabio Luis Barbosa. Uma história da onda progressista sulamericana (1998-2016). São Paulo: Elefante, 2019.

SARDINHA, Edson. Brasil pode virar Venezuela em um ano e meio, diz Guedes. Congresso em foco, Economia, 2020. Disponível em: https://bit.ly/3fh5cxT, acesso em: 18/03/2021.

SCHURSTER, Karl; ARAUJO, Rafael. A Venezuela entre 1989 e 2013: crises, rupturas e continuidades. In: SCHURSTER, Karl; ARAUJO, Rafael (Org.). A era Chávez e a Venezuela no tempo presente. Rio de Janeiro: Autografia/Edupe, 2015.

TRIPATHI, Anurag; SB, Girisanker. A rivalidade de recursos dos EUA e da Rússia no contexto da crise venezuelana contemporânea: os perigos do rentier petro-state. Austral. Brazilian Journal of Strategy \& International Relations, v. 9, p. 92-110, 2020.

UZCÁTEGUI, Rafael. Venezuela, imperialismo e militarização. Open Democracy, Democracia abierta, 2020. Disponível em: https://bit.ly/3lRNe6d, acesso em: 18/03/2021.

. Corrida armamentista ou modernização de armamentos na América do Sul: estudo comparativo dos gastos militares. Estudos e Cenários, Observatório Político Sul-Americano. Rio de Janeiro: Iuperj, 2008.

VAZ, Alcides Costa. A crise venezuelana como fator de instabilidade regional. Análise Estratégica CEEEx, v. 3, 2017.

VIANA, Natalia. A desastrosa Operação do Exército que levou a morte Evaldo Rosa. UOL, Notícias, 2020. Disponível em: https://bit.ly/3lWcN6h, acesso em: 18/03/2021.

VILLA, Rafael Duarte. Venezuela: mudanças políticas na era Chávez. Estudos Avançados, v. 19, p. 153-172, 2005. Disponível em: https://bit.ly/3tGFXZF, acesso em: 18/03/2021.

ZANINI, Fábio. Candidatos a prefeito em Boa Vista usam retórica antivenezuelanos em campanha. Folha de São Paulo, Mundo, 2020. Disponível em: https://bit.ly/3cCCnKg, acesso em: 18/03/2021.

ZUKER, Fábio. Brasileiros e venezuelanos: uma crônica de ódio e compaixão. Agência Pública, Crônica, 2018. Disponível em: https://bit.ly/3cxmo1M, 
Revista Brasileira de História \& Ciências Sociais - RBHCS

Vol. 13 No 26, Janeiro - Junho de 2021

acesso em: 18/o3/2021.

ZERO, Marcelo. Para entender a Venezuela. Carta Capital, Brasil Debate, 2017. Disponível em: https://bit.ly/3tGFXZF, acesso em: 18/03/2021.

WEISBROT, Mark; SACH, Jeffrey. Sanções Econômicas como Punição Coletiva: O Caso da Venezuela. Center for Economic and Policy Research, maio de 2019. Disponível em: https://bit.ly/3s87hjo, acesso em: 18/03/2021.

Recebido em Abril de 2021 Aprovado em Setembro de 2021 